\title{
ANÁLISE SOCIOECONÔMICA DE PRODUTORES FAMILIARES DE CAPRINOS E OVINOS NO SEMIÁRIDO CEARENSE, BRASIL
}

\author{
SOCIOECONOMIC ANALYSIS OF SMALLHOLDER PRODUCING GOATS AND SHEEPS \\ IN THE SEMIARID CEARENSE, BRAZIL
}

\author{
Farias, J.L. de S. ${ }^{1 *}$; Araújo, M.R.A. de ${ }^{1}$; Lima, A.R. ${ }^{1}$; Alves, F.S.F. ${ }^{1}$; Oliveira, L.S. ${ }^{1}$ \\ e Souza, H.A. de ${ }^{1}$
} ${ }^{1}$ Empresa Brasileira de Pesquisa Agropecuária. Embrapa Caprinos e Ovinos. Sobral, CE. Brasil.
*jorge.sales@.embrapa.br

\section{PALAVRAS CHAVE ADICIONAIS}

Pequenos ruminantes. Desenvolvimento rural sustentável. Análise multivariada.

\section{RESUMO}

O objetivo deste estudo foi caracterizar e descrever sob o ponto de vista social e econômico os sistemas de produção das unidades familiares que utilizam a caprinocultura e a ovinocultura como atividades pecuárias no sistema de produção familiar no Estado do Ceará, Brasil. Os dados foram coletados a partir de 120 entrevistas com agricultores familiares produtores de caprinos e ovinos durante o ano de 2008, por meio de um questionário que apresentava aspectos sociais, econômicos, ambientais e produtivos. Para o estabelecimento da tipologia foram utilizadas técnicas estatísticas multivariadas (análise fatorial pelo método de componente principal) e, em seguida, utilizou-se a análise de agrupamento não hierárquico para a identificação de grupos homogêneos e caracterização da amostra das propriedades familiares. Foram identificados quatro grupos (I, II, III e IV) de famílias que utilizam os pequenos ruminantes como componentes em seus sistemas de produção. As famílias identificadas nos grupos II e III apresentaram como principal fonte de renda as atividades relacionadas ao uso da terra e as dos grupos I e IV demonstraram a fonte externa como componente central de suas finanças. O tamanho médio dos estabelecimentos familiares foi de 47,2 hectares (ha). Dos entrevistados $75,8 \%$ se consideraram alfabetizados e 93,3\% estavam envolvidos com alguma forma de associativismo. Os sistemas de produção utilizados pelos agricultores familiares eram diversificados, em relação às atividades exercidas

\section{AdDiTIONAL KEYWORDS}

Small ruminants. Sustainable rural development. Multivariate analysis.

pela família no meio rural. As atividades agropecuárias exercidas nas propriedades estiverem relacionadas com a garantia de produção de alimentos para o autoconsumo familiar e para 0 acesso a mercados locais. A heterogeneidade no uso da terra implicou em diferentes estratégias para adequar a realidade local, reflexo das dinâmicas internas e externas à propriedade, com consequências à reprodução social familiar.

\section{SUMMARY}

The objective of this study was to characterize and describe the socioeconomic profile of the system production of family farms that use goats and sheeps as components of household in the state of Ceara, Brazil. Data were collected from 120 interviews with family farmers producing goats and sheep during the year 2008, through a questionnaire that had social, economic, environmental and productive. To establish the typology were used multivariate statistical techniques (factor analysis by the method of principal component) and then used the nonhierarchical cluster analysis to identify homogeneous groups and characterization of the sample of family farms. There were four groups (I, II, III and IV) family of small ruminants using as components in their production systems. The families identified in groups II and III were the main source of income activities related to land use and those of groups I and IV showed the external source as a central 
component of your finances. The average size of the family farms was 47.2 hectares (ha). $75.8 \%$ of respondents considered themselves literate and $93.3 \%$ were involved with some form of association. The production systems used by farmers were diversified in relation to the activities performed by the family in rural areas. The agricultural activities are carried on the properties related to the security of food production for self and family for access to local markets. The heterogeneity in land use resulted in different strategies to suit local circumstances, reflecting the internal dynamics and external to the property, with consequences for social reproduction of the family.

\section{INTRODUÇÃO}

A agricultura familiar é um dos segmentos da agricultura brasileira que deve ser considerada como estratégica para o desenvolvimento rural local. De acordo com França et al. (2009), 84,4 \% dos estabelecimentos rurais brasileiros são familiares, ocupando 24,3 \% da área ocupada pelos estabelecimentos brasileiros, responsável por $38 \%$ do valor bruto da produção(VBP) da agropecuária nacional e a principal fonte geradora de empregos no meio rural. No entanto, uma parcela significativa destas unidades familiares encontrase à margem da modernização, verificandose uma exclusão tanto do ponto de vista tecnológico como de renda (Alves et al., 2005). Silva Júnior et al. (2011), afirmam que a agricultura familiar ainda enfrenta vários obstáculos, destacando-se a inexistência ou a indisponibilidade de serviços e informações adequadas às suas necessidades, que são vitais para a sustentabilidade das unidades de produção familiar.

A Região Nordeste é caracterizada pelo Semiárido Brasileiro (SAB), abrangendo aproximadamente 60 \% da sua área geográfica, com percentuais variáveis nos diferentes estados (Araújo Filho, 2006b). De acordo com Silva et al. (2010), apresenta como característica forte insolação, temperaturas relativamente altas e regime de chuvas marcado pela escassez, irregularidade e concentração das precipitações em breves períodos. Araújo Filho (2006a), afirma que a temperatura varia de um mínimo de $22{ }^{\circ} \mathrm{C}$ a máximo de $34{ }^{\circ} \mathrm{C}$, a precipitação pluvial de 250 a 1000 mm e a evapotranspiração potencial situa-se em torno de 2700 mm/ano, caracterizando um déficit hídrico elevado. Segundo Malvezzi (2007), é considerado como uma das regiões semiáridas do planeta mais habitado e com maior pluviosidade, entretanto é uma das mais pobres, cerca de dois terços da população encontra-se neste estado, abrigando metade dos estabelecimentos de base familiar do país, que se dedicam diretamente a atividades agropastoris, utilizando os recursos naturais existentes em suas propriedades como estratégia de convivência com o local.

A caprinocultura e a ovinocultura são alternativas pecuárias para as regiões áridas e semiáridas do planeta, principalmente devido à capacidade destes animais em se adaptarem a estas condições (Silva e Guimarães Filho, 2006; Martins et al., 2012), constituem em fontes de renda e de segurança alimentar para populações com elevado risco de exclusão social. No Nordeste brasileiro concentra-se aproximadamente $93 \%$ e $56 \%$ do efetivo nacional de caprinos e ovinos (IBGE, 2010), respectivamente. Atualmente, a produção de pequenos ruminantes caracteriza-se como uma atividade de grande importância cultural, social e econômica para a região, desempenhando um papel crucial no desenvolvimento do Nordeste (Costa et al., 2008).

O debate atual sobre o desenvolvimento rural, e recentemente sobre o desenvolvimento territorial, fundamenta-se, entre outros aspectos, na observação da persistência interligada da pobreza rural e da desigualdade social e regional, e enquadrase na discussão mais ampla sobre o desenvolvimento econômico e a sustentabilidade (Leite, 2010). Holanda Júnior (2006), aborda a necessidade de identificar grupos homogêneos de produtores e

Archivos de zootecnia vol. 63, núm. 241, p. 14. 
reconhecer os fatores que provocam as diferenciações entre os mesmo, com a finalidade de propor ações para o desenvolvimento local. Assim, faz-se necessário, a compreensão do contexto local, em suas diferentes dimensões, para a orientação de políticas para o desenvolvimento rural e a superação da pobreza.

O Estado do Ceará apresenta-se com o maior percentual de áreas semiáridas em seu território, $89 \%$ dos estabelecimentos rurais são de base familiar com atividades agropecuárias diversificadas e, segundo Campos (2004), variam de acordo com a microrregião considerada. A pecuária de caprinos e ovinos está presente em 10 \% e $16 \%$ dos estabelecimentos rurais do Estado, respectivamente, merecem destaque, tanto pela área ocupada quanto pela elevada significação social e econômica para a agricultura familiar do Estado. Contudo, ainda são escassas as informações sobre o perfil e a situação socioeconômica dos agricultores familiares produtores de caprinos e ovinos, sua caracterização possibilitará a elaboração de políticas públicas para o setor como para os próprios agricultores.

Este estudo tem como objetivo caracterizar e descrever sob o ponto de vista social e econômico os sistemas de produção das unidades familiares que utilizam a caprinocultura e a ovinocultura como atividades pecuárias no sistema de produção familiar no Estado do Ceará.

\section{MATERIALE MÉTODOS}

\section{DESCRIÇÃO DAÁREADEESTUDO}

A realização do estudo ocorreu em sete municípios: Apuiarés, Campos Sales, Farias Brito, Independência, Pentecoste, Tauá e Tejuçuoca, abrangendo os territórios do Cariri, Inhamuns-Crateús e vales do Curu e Aracatiaçu que em conjunto contemplam $38 \%$ das propriedades que produzem pequenos ruminantes no Estado do Ceará.
O território do Cariri é formado por 27 municípios, com 29,8 \% da população habitando a área rural e tem índice de desenvolvimento humano (IDH) médio de 0,66 . Está localizado na parte sul do Estado. Apresenta clima semiárido, com chuvas irregulares e pluviosidade média em torno de $700 \mathrm{~mm} / \mathrm{ano}$, sendo que de janeiro a abril se concentram $80 \%$ das chuvas. A temperatura média anual fica entre $21^{\circ} \mathrm{Ce} 27^{\circ} \mathrm{C}$. Possui vegetação diversificada em função das condições de solo e clima, com a predominância das seguintes vegetações: Floresta caducifólia espinhosa, Caatinga arbustiva e Carrasco. Foram selecionados para a pesquisa os municípios de Campos Sales e Farias Brito que representam 38,7 \% do efetivo de caprinos e ovinos do território.

O território Inhamuns-Crateús composto por 20 municípios, está localizado na região sudoeste, oeste, centro oeste e noroeste do Estado do Ceará do Estado, com 44,9 \% da população vivendo em áreas rurais e IDH médio de 0,64 . O clima é caracterizado como semiárido, com baixa umidade e volume pluviométrico médio entre 300 a $800 \mathrm{~mm} /$ ano, temperatura média anual de $26{ }^{\circ} \mathrm{C}$, com pequena variação interanual, mas com ampla variação diária. A vegetação sofre a influência direta do clima, da pluviosidade e dos solos, por isso apresenta-se típica, com Caatinga arbustiva, Floresta caducifólia espinhosa, Floresta subcaducifólia Tropical pluvial e Carrasco. Os municípios selecionados foram Tauá e Independência que representam 39,9\% do efetivo de caprinos e ovinos do território.

O território dos vales do Curu e Aracatiaçu é constituído por 18 municípios, localizado na porção noroeste do estado, 45,4 \% da população habita áreas rurais e apresenta o IDH médio de 0,63. Caracterizase por ser uma região que apresenta sistemas ecológicos distintos com litoral, serra e sertão. Entretanto, para este estudo consideramos apenas o sistema ecológico do bioma Caatinga, que é caracterizado pela depressão sertaneja e a caatinga arbustiva 
densa e aberta, possibilitando diferentes condições para a exploração produtiva. Ocorre a predominância do clima semiárido quente com temperaturas média anual de 33 ${ }^{\circ} \mathrm{C}$. O índice pluviométrico apresenta valores médios entre 430 a 895 mm/ano, distribuindo-se entre os meses de Janeiro e Junho. Foram selecionados três municípios que representam de forma significativa o sistema ecológico do sertão para a realização da pesquisa: Tejuçuoca, Apuiarés e Pentecoste que representam 62,3\% do rebanho de pequenos ruminantes do território.

\section{ColetAde dAdOS E ANÁLISE ESTATísticA}

Para este estudo utilizou-se os conceitos de agricultura familiar definido pela Lei da Agricultura Familiar, Lei n ${ }^{\circ} 11326$ (França et al., 2009) e o de sistema de produção, entendido como a combinação, no espaço e no tempo, de certa quantidade de força de trabalho e de distintos meios de produção com a intenção de obter produções agrícolas ou não agrícolas (Miguel et al., 2007).

Para a determinação do tamanho da amostra levou em consideração a estimativa da proporção de propriedades de agricultura familiar que utilizam a produção de pequenos ruminantes no Estado do Ceará. Dessa forma, foram realizadas 120 entrevis- tas com agricultores familiares que continham em seus sistemas de produção as atividades de caprinos e ovinos durante o ano de 2008, tendo sido utilizado um questionário envolvendo aspectos sociais, econômicos, ambientais e produtivos. Os produtores foram selecionados aleatoriamente dentro de cada município, a partir da identificação pelas instituições locais nos referidos territórios, sendo os questionários distribuídos conforme a proporção de unidades familiares que apresentassem a produção e pequenos ruminantes.

Utilizou-se as técnicas multivariadas de análise fatorial e de agrupamentos (Castel et al., 2003; Milan et al., 2003; Ruiz et al., 2009; Sepúlveda et al., 2010; Gaspar et al., 2011), além de estatísticas descritivas para a análise dos dados. Inicialmente foram consideradas 22 variáveis, após análise da medida de adequação da amostra (MSA) e comunalidade verificou-se a adequação da análise fatorial reduzindo para 10 variáveis, sendo selecionadas para a formação dos grupos: tamanho da propriedade (hectare), mão-de-obra (somatório da mão-de obra familiar e contratada utilizada anualmente na unidade de produção), receita agropecuária (somatório da renda monetária anual obtida da venda de produtos agríco-

Tabela I. Pesos fatoriais e comunalidades após extração pelo método das componentes principais. (Fatorial weights and communalities after extraction by the method of principal components).

\begin{tabular}{lcccc}
\hline Variáveis & \multicolumn{2}{c}{ Fator } & Comunalidade \\
& PC1 & PC2 & PC3 & \\
\hline Receita agropecuária (R\$) & 0,864 & $-0,123$ & $-0,053$ & 0,765 \\
Instalações (\%) & 0,658 & 0,030 & $-0,038$ & 0,436 \\
Bovinos carne (\%) & 0,627 & $-0,189$ & 0,304 & 0,522 \\
Bovinos derivados de leite (\%) & 0,623 & 0,330 & 0,123 & 0,512 \\
Grãos (\%) & 0,532 & $-0,121$ & $-0,492$ & 0,541 \\
Caprinos carne (\%) & 0,024 & 0,763 & $-0,133$ & 0,601 \\
Bovinos leite (\%) & 0,277 & 0,530 & 0,452 & 0,563 \\
Ovinos (\%) & 0,228 & $-0,805$ & 0,120 & 0,714 \\
Tamanho da propriedade (hectare) & 0,172 & $-0,027$ & 0,702 & 0,523 \\
Mão-de-obra (unidade/homem) & 0,094 & 0,170 & $-0,630$ & 0,435 \\
\hline
\end{tabular}

Archivos de zootecnia vol. 63, núm. 241, p. 16. 
las, aluguel de terra e venda de esterco com a renda anual do autoconsumo familiar), infraestrutura (percentual de instalações agropecuárias existentes na propriedade), bovinos carne (percentual de propriedades destinadas a produção de carne), bovinos leite (percentual de propriedades destinadas para produção de leite in natura), bovinos derivados leite (percentual de propriedades com finalidade de produção de derivados de leite), caprinos carne (percentual de propriedades destinada a produção de carne), ovinos (percentual de propriedades destinada a produção de carne) e grãos (percentual de propriedades destinada a produção de grãos). Em seguida, utilizou-se a análise de agrupamento não hierárquico de clusters para a identificação de grupos homogêneos, tendo como base o valor da estatística cubic clustering criterion (CCC) (Khattree e Naik, 2000). Para todas as análises foi utilizado o Statistical Analysis Systems 9.2 (SAS, 2009).

\section{RESULTADOSEDISCUSSÃO}

\section{ANÁLISE FATORIAL}

Foram retidos três fatores que apresentavam um eigenvalue igual ou superior a 1 e a percentagem de variância retida. Assim, optou-se pela utilização de dois critérios para a retenção de fatores estando, de acordo com Marôco (2010), uma vez que, este afirma que a utilização de um único critério pode levar à retenção de mais ou menos fatores que poderão não ser relevantes para descrever a estrutura latente. Os três fatores explicaram 56,18 \% da variância total. Assim, o primeiro fator é designado como Atividades agropecuárias tradicionais, o segundo como Atividades pecuárias emergentes e o terceiro como Fatores de produção familiar (tabela I).

O primeiro fator explica 24,46\% da variância. Este apresentou alta e positiva correlação entre as variáveis receitas agropecuárias, instalações, bovinos para produção de carne, bovinos para a produção de derivados de leite e a produção de grãos. Este fator é indicativo de que a receita agropecuária da unidade familiar está relacionada positivamente com a presença de diferentes instalações na propriedade e com a utilização de atividades agropecuárias tradicionais na região, como a pecuária bovina e a produção de grãos.

O segundo fator explica 17,13\% da variância. Este fator apresentou uma correlação negativa entre às variáveis relacionadas com a produção de carne de ovinos e caprinos. É provável que estas duas atividades sejam conflitantes dentro de um sistema de produção familiar, ou seja, diferentes fatores poderão está contribuindo para uma especialização das atividades, podendo está ligada a dinâmica externa a propriedade, como a inserção dos produtos em mercados locais ou a aspectos relacionados com a própria resiliência animal às adversidades do semiárido.

O terceiro fator explica $14,59 \%$ da variância. Apresentou correlação negativa entre utilização de mão de obra pela unidade familiar e o tamanho da propriedade. Sendo um indicativo que a utilização de mão-deobra, familiar e contratada, está relacionada com o tamanho da propriedade. Verificouse que a utilização de mão-de-obra contratada ocorreu de forma eventual e apenas para complementar o trabalho familiar.

\section{ANÁLISE DE CLUSTERS}

A análise de agrupamento possibilitou a identificação de quatro grupos homogêneos que utilizam a caprinocultura e/ou ovinocultura nos sistemas de produção familiar (tabela II). Os agrupamentos II e IV concentraram-se no território do InhamunsCrateús, os agrupamentos I e IV no território vales do Curu e Aracatiaçu e o território do Cariri predominou o agrupamento III.

Os grupos formados apresentaram sistema de produção misto, isto é, formados pela agricultura e pecuária, estando de acordo com o estudo de Costa et al. (2008), 
realizado no Estado da Paraíba, Brasil.

\section{Grupo I: Produção de caprinos}

Este grupo caracterizou-se pela pecuária, destacando-se a caprinocultura como o principal componente do sistema. Os caprinos foram produzidos em 94,1 \% das propriedades, com tamanho médio do rebanho de 40,5 $\pm 23,6$ animais, produzidos principalmente para a produção de carne, sendo utilizados pelas famílias tanto para o autoconsumo (82,3\%) como para acessar mercados (88,3 \%). Verificou-se em 5,8 \% das unidades familiares a produção de derivados de leite caprino como uma alternativa para acessar mercados. A ovinocultura esteve presente em apenas 5,8 \% das propriedades, não foi identificada a forma de utilização desse segmento para a família no ano de 2008. As unidades familiares utilizaram a bovinocultura (58,8 \%) com o propósito de produção de leite, este foi utilizado para o autoconsumo e para inserção em mercados. A produção de grãos esteve presente em 64,7 \% das propriedades, os grãos produzidos foram o feijão (64,7 \%), milho (58,8 \%) e a fava (17,6\%), estes sendo utilizados, principalmente, para o consumo interno da unidade familiar.

\section{Grupo II: Produção de bovinos e ovinos}

Este grupo apresentou como característica a produção de bovinos e ovinos, presente em $100 \%$ das unidades. Os bovinos destinaram-se a produção de leite, direcionada para o consumo familiar e ao acesso aos mercados. A produção de ovinos apresentou o tamanho médio do rebanho 75,0 $\pm 90,2$, com o mínimo de 11 e máximo de 296 animais, sendo utilizada em todas as unidades como alternativa de renda, pois $100 \%$ das famílias afirmaram produzir ovinos para acessar mercados, embora, também foram utilizados para o consumo familiar (77,8 \%). A produção de caprinos esteve presente em $66,7 \%$ das unidades familiares, o efetivo médio do rebanho foi de $17 \pm 19,5$, com valor máximo de 57 animais, sendo utilizados para o consumo familiar (33,3\%) e geração de renda (66,7\%). A caprinocultura e a ovinocultura foram atividades destinadas a produção de carne. A agricultura esteve presente em 89,9 \% das propriedades, a produção de grãos foi diversificada produzindo milho (55,5\%), feijão $(44,4 \%)$, mamona (11,1\%), fava (11,1\%) e arroz $(11,1$ $\%)$, estes foram utilizados, principalmente, para o consumo interno da unidade familiar (77,8 \%), todavia 55,5\% das famílias obti-

Tabela II. Características gerais das unidades familiares produtoras de pequenos ruminantes no semiárido cearense. (General characteristics of households producing small ruminants in semiarid the of Ceara).

\begin{tabular}{lcccr}
\hline Características & \multicolumn{4}{c}{ Grupos } \\
\hline Famílias (\%) & I & II & III & IV \\
Idade (anos) & 14,2 & 7,5 & 55,8 & 22,5 \\
Área média das unidades familiares (ha) & 43,7 & 39,8 & 46,6 & 47,0 \\
Mão-de-obra familiar (homens) & 34,9 & 86,8 & 39,1 & 61,7 \\
Mão-de-obra contratada (homens) & 3,3 & 3,0 & 2,7 & 2,8 \\
Alfabetizados (\%) & 0,7 & 0,9 & 0,6 & 0,7 \\
Participação em associação (\%) & 94,2 & 88,8 & 67,2 & 81,5 \\
Participação em capacitações (\%) & 88,3 & 88,9 & 95,5 & 92,5 \\
Fonte permanente de água (\%) & 88,3 & 66,7 & 74,6 & 85,2 \\
Energia elétrica (\%) & 64,7 & 100 & 94,0 & 88,9 \\
& 94,1 & 100 & 100 & 92,5 \\
\hline
\end{tabular}

Archivos de zootecnia vol. 63, núm. 241, p. 18. 
veram renda a partir da venda de grãos.

\section{Grupo III: Produção de grãos}

Este grupo apresentou como característica da propriedade a produção de grãos. A agricultura esteve presente em 98,5 \% das propriedades, a produção de grãos, semelhante ao grupo anterior, foi diversificada produzindo milho (85 \%), feijão (82,1\%), fava (34,3\%), amendoim (1,5\%) e arroz (1,5 $\%)$, estes foram utilizados, principalmente, para o consumo interno da unidade familiar (92,5 \%), contudo 70,1\% afirmaram que obtiveram renda a partir da venda de grãos. A atividade pecuária mista, com destaque para a produção de ovinos (98,5 \%), que apresentou o tamanho médio do rebanho 38,5 $\pm 25,1$, com o máximo de 136 animais, foram utilizados como alternativa de renda em $89,5 \%$ das unidades familiares, entretanto, $91 \%$ das famílias afirmaram produzir ovinos para o consumo familiar. A produção de bovinos (67,1 \%) foi utilizada para a produção de leite, destinando-se ao consumo familiar e ao acesso aos mercados, como alternativa de geração de renda. A caprinocultura $(29,8 \%)$ teve sua finalidade principalmente a produção de carne, sendo destinada para o consumo das famílias (20,9\%) e vendidos em 19,4\%. Entretanto, verificase que $3 \%$ dos produtores que afirmaram possuir caprinos, conduziram a atividade para a produção de leite com a finalidade de geração de renda e alternativa alimentar para a família. Outras atividades foram importantes para as famílias deste grupo, entre elas destacam-se a fruticultura e a produção de mel. Convém ressaltar que este foi um dos grupos mais diversificados na produção animal e vegetal.

\section{Grupo IV: Produção de ovinos}

Este grupo apresentou no sistema de produção apenas a pecuária, não ocorrendo a produção de grãos, sendo o sistema restrito a produção animal. A ovinocultura apresenta-se como a forma de pecuária predominante, presente em $100 \%$ das unidades familiares, sendo umas das principais alternativas de geração de renda para estas famílias (81,5\%), utilizada como fonte de alimentação (77,8 \%). A produção de bovinos, presente em $70 \%$ das unidades, semelhante aos grupos anteriores, esteve destinada a produção de leite, destinada preferencialmente para o consumo familiar, porém em menor importância, para acessar mercados. A caprinocultura foi uma atividade destinada a produção de carne. A produção de caprinos esteve presente em $51,8 \%$ das unidades familiares apresentou o tamanho médio do rebanho 12,2 $\pm 15,5$, com o máximo de 45 animais, sendo utilizados como alternativa de renda (18,5\%) e consumo familiar (29,6\%). Outras atividades foram importantes para o sistema de produção familiar como a produção de mel e de ovos.

A diversificação nas atividades rurais observadas nos grupos é, provavelmente, um importante componente para a resiliência do sistema de produção como forma de manter a autonomia familiar nos territórios estudados. As atividades agropecuárias exercidas nas propriedades estiverem relacionadas tanto com a garantia de produção de alimentos para o autoconsumo familiar, como para o acesso a mercados locais, demonstrando que a produção familiar não apresenta uma lógica mercantil. Portanto, está de acordo com Abramovay (2004) que afirmou a inexistência de uma separação lógica dos recursos da família daqueles que vão especificamente ao empreendimento econômico. Como exemplo, citamos a caprinocultura e ovinocultura como atividades pecuárias importantes para o sistema de produção familiar, uma vez que a importância dos pequenos ruminantes esteve relacionada à segurança alimentar, bem como, apresentou-se como uma das alternativas de renda para as famílias estudadas.

A identificação de grupos homogêneos consolida-se como uma estratégia para a abordagem territorial no meio rural, pois contemplou a existência de uma diversidade 
de sistemas de produção familiar. Estando de acordo com Buainain et al. (2003), quando afirmam que a agricultura familiar é um universo profundamente heterogêneo, seja em termos de disponibilidade de recursos, acesso ao mercado e capacidade de geração de renda.

\section{Aspectos SOCIAIS}

Foi verificado o capital social dos agricultores familiares produtores de caprinos e ovinos, sendo que este foi compreendido como a expressão de dinâmica de organização, confiança, cooperação, iniciativa, solidariedade e participação dos indivíduos de forma efetiva na formação de um senso de responsabilidade da própria comunidade sobre seus rumos, manifestando-se em ganhos concretos sobre a resolução de seus problemas (Araújo, 2010).

A capacidade de associar-se foi observada em 93,3 \%. As associações comunitárias (75\%) foram as principais formas de associativismo encontrado nos grupos, variaram de 41,2 no grupo I até $85 \%$ no grupo III. Outras formas de associativismo encontrado foram através do Sindicato dos Trabalhadores e Trabalhadores Rurais (STTR) (40 \%) e Cooperativa (5,8 \%). A capacidade de colaboração entre as pessoas para atuarem de forma conjunta, por meio de grupos e organizações, contribuíram para a melhoria na qualidade de vida das famílias. As associações locais foram importantes para que as comunidades conquistassem benefícios relacionados, principalmente com a infraestrutura, tais como energia elétrica.

Verificou-se o nível de escolaridade do agricultor, sendo que 75,8 \% dos entrevistados se consideraram alfabetizados, ou seja, expressaram que sabiam ler e escrever. A formação escolar do agricultor familiar no semiárido cearense foi semelhante ao encontrado por Hernández et al. (2011). Dessa forma, observa-se a necessidade de promover uma ampliação do processo de alfabetização para adultos, sendo expressivo o número de agricultores familiares entre- vistados que não concluíram o ensino fundamental, variando entre 88,5 \% (grupo II) a 96,3 \% (grupo IV). Ressalta-se que este tipo de privação poderá constituir-se em um dos obstáculos para o desenvolvimento rural sustentável, conforme Mendonça (2009). Para assegurar o desenvolvimento local deve-se ter em pauta o fortalecimento do capital social, pois de acordo com Ferraz et al. (2011), este é um bem coletivo que se constitui por meio da convergência de objetivos e da produção de resultados viabilizados por relações sociais proporcionando o acesso de indivíduos e de organizações a recursos intelectuais, institucionais e materiais.

\section{Aspectos ECONÔMICOS}

O tamanho médio dos estabelecimentos familiares foi de 47,2 hectares (ha), sendo que estes variaram de um hectare (ha) (grupo I) para 202 (ha) (grupo III). A área média das propriedades dos grupos formados encontrava-se acima do tamanho médio de 12 hectares (Brasil, 2009) para os estabelecimentos de base familiar da Região Nordeste. Provavelmente este é um dos fatores mais importantes para a reprodução familiar, pois o tamanho da unidade familiar poderá decidir o que e como explorar as diferentes atividades agropecuárias. Silva e Guimarães Filho (2006), afirmam que a estrutura fundiária é um dos principais fatores responsáveis pela baixa eficiência dos sistemas produtivos da agricultura familiar do semiárido. Entretanto, Buainain et al. (2005), afirmam que o tamanho do estabelecimento, não é suficiente para revelar a viabilidade ou potencialidade da exploração sustentável das unidades familiares, que depende da fertilidade do solo, da localização, do sistema de produção adotado, das tecnologias empregadas, do acesso a mercados.

A mão-de-obra utilizada nas unidades familiares contou com a participação de membros das famílias e da contratação de membros externos a propriedade. Verifica- 


\section{CAPRINOCULTURA E OVINOCULTURA E CONVIVÊNCIA COM O SEMIÁRIDO}

se que a mão-de-obra familiar presente variou de um a 12 (Unidades/Homem), sendo que $75,3 \%$ das unidades familiares apresentaram de um a três Unidades/Homem. A mão-de-obra externa à propriedade esteve presente em apenas 30,8 \% das unidades familiares, sendo que esta variou de um a nove (Unidade/Homem). Dessa forma, a agricultura familiar nos territórios estudados é a principal geradora de emprego rural, estando de acordo com o Censo Agropecuário realizado em 2006 (Brasil, 2009) que apontou a agricultura familiar absorvendo $74,4 \%$ da mão de obra e com uma média de 2,6 pessoas ocupadas no campo.

O nível de infraestrutura presente na propriedade foi um dos itens avaliados, os produtores familiares afirmaram possuir armazém (28,7\%), estábulos (27,8\%), currais $(63,9 \%)$, apriscos (81,2\%) e silos (32,8\%). Nos grupos I, III e IV verificou-se a baixa priorização pelo armazenamento de alimentos para o rebanho, a unidade familiar apresentou dependência de alimentação para os animais a partir de pastagem nativa (Macedo et al., 2012), e provavelmente de insumos externos para manter o desempenho produtivo animal nos meses secos do ano, comprometendo a renda e a segurança alimentar das famílias. Outro ponto observado foi a infraestrutura relacionada a captação e armazenamento de água. Constatou-se que 89,2 \% dos entrevistados afirmaram possuir fontes de água que apresentem disponibilidade para o fornecimento em um período de 12 meses. Verificou-se que tal disponibilidade variou de 64,7 \% (grupo I) para 100 (grupo II). As formas de captação de água foram açudes (68,3 \%), cisternas (61,7\%) e poços (23,3\%). Diante de cenário de mudanças climáticas, com aquecimento global com projeções de intensificação da aridez e aumento da frequência de fenômenos extremos que implicará na incidência de secas mais fortes na região (Brito et al., 2010), verificou-se a baixa utilização de técnicas de conservação de água, com apenas três formas de arma- zenamento, o que expõem as famílias a uma insegurança hídrica, tanto sob o ponto de vista do consumo humano quanto da produção de alimento e dos animais. A necessidade de implantação de programas nas regiões estudadas poderá colaborar para a sustentabilidade local por meio de alternativas tecnológicas que reduzam a vulnerabilidade das famílias em momentos de escassez.

As rendas obtidas pelas famílias estiverem relacionadas a receitas obtidas a partir das atividades agropecuárias e receitas externas a propriedade. As receitas agropecuárias foram calculadas, semelhante ao preconizado por Holanda Júnior (2004), que utilizou o somatório da renda monetária (soma das receitas anuais com as vendas de produtos e aluguel de terra e animais e venda de esterco) com a renda do autoconsumo (receita bruta anual que teria sido obtida se os produtos consumidos nas propriedades tivessem sido vendidos). As principais atividades geradoras de renda para as famílias estiveram relacionadas à produção de grãos e a pecuária bovina, caprina e ovina. A caprinocultura destacou-se como a principal atividade geradora de renda para o grupo I. As famílias pertencentes aos agrupamentos III e IV tiveram como principal atividade a ovinocultura. A bovinocultura foi a atividade pecuária com maior destaque para o grupo II. Verificou-se que a produção de grãos foi a principal fonte de renda para as famílias dos agrupamentos I e III. As receitas externas obtidas pelas famílias entrevistadas estiveram relacionadas a transferências governamentais, tais como aposentadoria (26,6 \%) e a programas sociais (53,3 \%), como o Programa Bolsa Família, além de outras atividades como a venda de mão-de-obra (4,2\%), empregos (10,8\%) e microempreendedorismo (2,5\%), e até mesmo doações (0,8\%). As famílias pertencentes aos agrupamentos I e IV apresentaram-se dependentes de fontes externas a propriedade. Em contraposição, as famílias dos agrupamentos II e III apre- 
sentaram como principal fonte de renda as atividades agropecuárias. Provavelmente, deverá existir uma relação direta entre o grau de diversificação do sistema de produção familiar com a sua dependência financeira. Ressalta-se que a intensidade no uso da terra poderá estar relacionada com fatores internos e externos a propriedade, com a infraestrutura hídrica, segurança alimentar, inserção em mercados locais e acesso a políticas públicas relacionadas ao desenvolvimento rural (Kassouf et al., 2004).

$\mathrm{O}$ acesso ao mercado foi por meio de iniciativas autônomas em mercados locais, com base em redes de proximidade. Foram identificadas três formas de acesso aos mercados, com o atravessador sendo a principal forma de intermediação dos produtos da agricultura familiar, venda direta aos consumidores e varejistas. Estudos sobre as estratégias de produção e a compreensão sobre a dinâmica dos mercados locais e de ciclo curto, poderão contribuir para o estabelecimento e fortalecimento de políticas públicas necessárias ao fortalecimento da agricultura familiar. De acordo com Wilkinson (2008), tais estudos devem ser orientados sobre normas técnicas como valores a serem negociados e da qualidade do produto como envolvendo as suas formas de produção e o estilo de vida em que se apoiam. Estes poderiam contribuir na identificação de produtos que possuíssem apelos para o reconhecimento de cada local ou territorial, um potencial a ser considerado como uma estratégia para o desenvolvimento rural sustentável. Dessa forma, devem-se buscar mecanismos para a construção social de mercados que possibilite as famílias o seu fortalecimento em relação aos canais tradicionais de comercialização, para que estes não sejam completamente dependentes do mercado.

$\mathrm{O}$ acesso a crédito por meio de empréstimos bancários foi mensurado e verificou-se que $62,5 \%$ dos entrevistados realizaram tais operações, destacando os grupos II e III que obtiveram índices de 79,1 $\%$ e $100 \%$, respectivamente, enquanto os grupos I e IV apresentaram baixo índice de utilização 35,3 \% e 25,9 \%. A dinamização do sistema de produção das famílias nos agrupamentos II e III poderá ter relações com o nível de acesso ao crédito, uma vez que estes foram os principais demandantes pelo acesso ao crédito via programa de fortalecimento da agricultura familiar (PRONAF). Por sua vez, as famílias dos grupos I e IV apresentaram baixa demanda por este tipo de política pública, provavelmente devido ao uso de menor intensidade das atividades agropecuária. Entretanto, de acordo com Damasceno et al. (2011), faltam estudos para avaliar o programa no que diz respeito à contribuição para o desenvolvimento sustentável dos agricultores familiares.

As famílias pertencentes aos grupos I e IV, provavelmente poderão se encontrar em situações de risco, uma vez que apresentaram em relação aos demais grupos, um menor uso da terra, baixo acesso ao crédito rural e dependência de renda externa. Tais fatores poderão comprometer sua reprodutibilidade social, econômica, política (Gehlen, 2004) e ambiental, contribuindo para o aumento das desigualdades sociais e pobreza rural.

\section{CONCLUSÃO}

Foram identificados quatro grupos de sistemas de produção de agricultores familiares de caprinos e ovinos no semiárido cearense, estes apresentaram como característica atividades diversificadas e relacionadas com a segurança alimentar e a inclusão produtiva de agricultores familiares em mercados locais.

Ocorreu uma heterogeneidade no uso da terra, implicando na existência de diferentes estratégias para adequar o sistema de produção com a realidade local, um reflexo das dinâmicas internas e externas a propriedade, com consequências sobre a 


\section{CAPRINOCULTURA E OVINOCULTURA E CONVIVÊNCIA COM O SEMIÁRIDO}

reprodução familiar.

Devem ser reorientadas ações para o fortalecimento da agricultura familiar, por meio do desenvolvimento de novas prática

\section{BIBLIOGRAFIA}

Abramovay, R. 2004. A densa vida financeira. In: R. Abramovay (Ed.). Laços financeiros na luta contra a pobreza. Annablume. São Paulo. pp. 21-70.

Alves, E.; Contini, E. e Hainzelin, E. 2005. Transformações da agricultura brasileira e da pesquisa agropecuária. Cadernos Ciênc Tecnol, 22: 37-51.

Araújo, J.B.C. 2010. Tradição e modernidade: o queijo de coalho artesanal como fonte de desenvolvimento territorial da Comunidade de Tiasol, Tauá-CE. Monografia (Especialização em Democracia Participativa, República e Movimentos Sociais). Universidade Federal de Minas Gerais. Belo Horizonte. 159 pp.

Araújo Filho, J.A. 2006a. Aspectos zooecológicos do caprino e do ovino nas Regiões Semiáridas. Embrapa Caprinos e Ovinos. Sobral. Embrapa Caprinos e Ovinos. Documentos, 61a. 28 pp.

Araújo Filho, J.A. 2006b. O bioma Caatinga. In: Sobrinho, J.F. e Falcão, C.L. da C. (Eds.) Semiárido: diversidades, fragilidades e potencialidades. Sobral Gráfica. Sobral. Brasil. pp. 49-70.

Brasil. 2009. Censo agropecuário 2006: agricultura familiar. primeiros resultados. IBGE. Rio de Janeiro. 267 pp.

Brito, L.T. de L.; Silva, A de S.; Silva, M.S.L. Da, Porto, E.R. e Pereira, L.A. 2010. Tecnologias para o aumento da oferta de água no Semiárido brasileiro. In: Sá, I.B e Silva, P.C.G da (Eds.) Semiárido brasileiro: pesquisa, desenvolvimento e inovação. Embrapa Semiárido. Petrolina. pp. 317-352.

Buainain, A.M.; Romeiro, A.R. e Guanziroli, C. 2003. Agricultura familiar e o novo mundo rural. Sociologias., 5: 312-347.

Buainain, A.M.; Guanziroli, C.; Souza Filho, H.M. e Bánkuti, F.I. 2005. Peculiaridades regionais da agricultura familiar brasileira. In: Souza Filho, H.M. e Batalha, M.O. (Eds.). Gestão Integrada da Agricultura familiar. São Carlos Universidade sociais que vislumbre a diversidade do meio rural e o contexto local, sob pena da ampliação da desigualdade e pobreza rural no semiárido cearense.

Federal de São Carlos. São Carlos. pp. 13-41. Campos, C.K. 2004. Arranjos produtivos locais: o Caso da caprino-ovinocultura nos municípios de Quixadá e Quixeramobim. Dissertação (Mestrado em Economia Rural). Universidade Federal do Ceará. Fortaleza. 97 pp.

Castel, J.M.; Mena, Y.; Delgado-Pertinñez, M.; Camuñez, J.; Basulto, J.; Caravaca, F.; GúzmánGuerrero, J.L. and Alcalde, M.J. 2003. Characterization of semi-extensive goat production systems in southern Spain. Small Ruminant Res, 47: 133-143.

Costa, R.G.; Almeida, C.C.; Pimenta Filho, E.C.; Holanda Júnior, E.V. e Santos, N.M. 2008. Caracterização do sistema de produção caprino e ovino na região semiárida do Estado da Paraíba. Brasil. Arch Zootec, 57: 195-205.

Damasceno, N.P.; Khan, A.S. e Lima, P.V.P. 2011. O impacto do Pronaf sobre a sustentabilidade da agricultura familiar, geração de empregos e renda no Estado do Ceará. Rev Econ Sociol Rural, 49: 129-156.

Ferraz, S.F. de S.; Gobb, R.L. e Lima, T.C.B. de. 2011. Teoria do capital social: um estudo no cluster moveleiro de Marco (CE). Rev Contextus, 9: 79-95.

França, C.G. de.; Del Grossi, M.E. e Marques, V.P.M. de A. 2009. O censo agropecuário 2006 e a agricultura familiar no Brasil. MDA. Brasília. $96 \mathrm{pp}$.

Gaspar, P.; Escribano, A.J.; Mesías, F.J.; Escribano, M. and Pulido, A.F. 2011. Goat systems of Villuercas-Ibores area in SW Spain: Problems and perspectives of traditional farming systems. Small Ruminant Res, 97: 1-11.

Gehlen, I. 2004. Políticas públicas e desenvolvimento social rural. São Paulo em Perspectiva, 18: 95-103.

Hernández, J.E.; Franco, F.J.; Villarreal, O.A.; Camacho, J.C. y Pedroza, R.M. 2011. Caracterización socioeconômica y productiva de unidades caprinas familiares em la Mixteca Pobla- 
na. Arch Zootec, 60: 175-182.

Holanda Júnior, E.V. 2004. Produção e comercialização de produtos caprinos e ovinos por agricultores familiares dos sertões baiano de São Francisco. Tese (Doutorado em Produção Animal). Universidade Federal de Minas Gerais. Belo Horizonte. 121 pp.

Holanda Júnior, E.V. 2006. Sistema de produção de pequenos ruminantes no Semiárido do Nordeste Brasileiro. Embrapa Caprinos e Ovinos. Sobral. Documentos, 66. 53 pp.

IBGE. 2010. Produção da Pecuária Municipal 2010. http://www.ibge.gov.br/home/estatistica/ economia/ppm/2010/comentarios.pdf (06/02/ 2012).

Leite, S.P. 2010. Governança das políticas públicas para o desenvolvimento territorial rural no Brasil. In: Moreira, R.J. e Bruno, R. (Eds.). Dimensões rurais de políticas brasileiras. Mauad. Rio de Janeiro. pp. 105-136.

Khattree, R. and Naik, D.N. 2000. Multivariate date reduction and discrimination with SAS software. Willy Inter-Science. Cary. 558 pp.

Kassouf, A.L.; Nunes, de A.A.; Pontili, R.M. e Rodrigues, F.A. 2004. Análise das políticas e programas sociais no Brasil. OIT/Programa IPEC América do Sul. Brasília. 108 pp.

Macedo, C.H.O.; Santos, E.M.; Da Silva, T.C.; De Andrade, A.P.; Da Silva, D.S.; Da Silva, A.P.G. e De Oliveira, J.S. 2012. Produção e composição bromatológica do sorgo cultivado (Sorghum bicolor) cultivados sob doses de nitrogênio. Arch Zootec, 61: 209-216.

Malvezzi, R. 2007. Semiárido: uma visão holística. Confea. Brasília. 140 pp.

Marôco, J. 2010. Análise estatística com o PASW Statistics (ex-SPSS). ReportNumber. Pêro Pinheiro. 953 pp.

Martins, E.C.; Albuquerque, F.H.M.R. de e Oliveira, L.S. 2012. Sistemas e custos de produção de ovinos de corte na agricultura familiar no Ceará. In: Guiducci, R.C.N.; Lima Filho, J.R. e Mota, M.M. (Eds.) Viabilidade econômica de sistemas de produção agropecuários: metodologia e estudos de casos. Embrapa. Brasília. pp.117-149.

Mendonça, K.V. de. 2009. Análise das causas socioeconômicas da pobreza rural no Ceará. Dissertação (Mestrado em Economia Rural). Uni- versidade Federal do Ceará. Fortaleza. 69 pp. Miguel, L. de A.; Mielitz Netto, C.G.A.; Nabinger, C.; Sanguiné, E.; Waquil, P.D. e Schneider, S. 2007. Caracterização socioeconômica e produtiva da bovinocultura de corte no Estado do Rio Grande do Sul. Rev Est Deb, 14: 95-125.

Milan, M.J.; Arnalte, E. e Caja, G. 2003. Economic profitability and typology of Ripollesa breed sheep farms in Spain. Small Ruminant Res, 49: 97-105.

Ruiz, F.A.; Mena, Y.; Castel, J.M.; Guinamard, C.; Bossis, N.; Caramelle-Holtz, E.; Contu, M.; Sitzia, M. e Fois, N. 2009. Dairy goat grazing systems in Mediterranean region: a comparative analysis in Spain, France and Italy. Small Ruminant Res, 85: $42-49$.

SAS®. 2009. User's Guide: Statistics. Version 8. SAS Institute Inc. Cary, NC. USA.

Sepúlveda, W.S.; Maza, M.T.; Pardos, L.; Fantova, E. e Mantecón, Á.R. 2010. Farmers' attitudes towards lamb meat production under a Protect Geografical Indication. Small Ruminant Res, 94: 90-97.

Silva, P.C.G. da e Guimarães Filho, C. 2006. Eixo tecnológico da ecorregião Nordeste. In: Sousa, I.S.F. de. (Ed.). Agricultura familiar na dinâmica da pesquisa agropecuária. Embrapa Informação Tecnológica. Brasília. pp. 109-161.

Silva, P.C.G. da S.; Moura, M.S.B. de.; Kiill, L.H.P.; Brito, L.T. de L.; Pereira, L.A.; Sá, I.B.; Correia, R.C.; Teixeira, A.H. de C.; Cunha, T.J.F. e Guimarães Filho, C. 2010. Caracterização do Semiárido brasileiro: fatores naturais e humanos. In: Sá, I.B. e Silva, P.C.G. da S. Semiárido Brasileiro: Pesquisa, Desenvolvimento e Inovação. Embrapa Semiárido. Petrolina. pp. 7-48.

Silva Júnior, C.D.; Martins, M.A.G.; Sicoli, A.H.; Balsadi, O.V. e Nascimento, P.P. Novos arranjos institucionais para o fortalecimento da agricultura familiar: uma abordagem territorial. In: Nascimento, P.P.; Sicoli, A.H.; Martins, M.A.G.; Balsadi, O.V. e Silva Júnior, C.D (Eds.). Inovações em desenvolvimento territorial: novos desafios para a Embrapa Embrapa Informação Tecnológica. Brasília. pp. 63-90.

Wilkinson, J. 2008. Mercados, redes e valores: o novo mundo da agricultura familiar. UFRGS. Porto Alegre. 213 pp. 